\title{
A New Approach of Gas Turbine Component Matching for Electrical Power Generation
}

\author{
Munzer S. Y. Ebaid ${ }^{1}$, Qusai Z. Al-Hamdan² \\ ${ }^{1}$ Department of Mechanical Engineering, Faculty of Engineering, Philadelphia University, Amman, Jordan \\ ${ }^{2}$ Aircraft Engineering Department, Perth College, University of the Highlands and Islands, Perth, Scotland, UK
}

Email address:

mebaid2@philadelphia.edu.jo (M. S. Y. Ebaid), qusai.al-hamdan.perth@uhi.ac.uk (Q.Z. Al-Hamdan)

\section{To cite this article:}

Munzer S. Y. Ebaid, Qusai Z. Al-Hamdan. A New Approach of Gas Turbine Component Matching for Electrical Power Generation. International Journal of Mechanical Engineering and Applications. Vol. 5, No. 4, 2017, pp. 214-222. doi: 10.11648/j.ijmea.20170504.15

Received: February 27, 2017; Accepted: March 7, 2017; Published: August 4, 2017

\begin{abstract}
Gas turbines are often required to operate at different power levels and under varying environmental conditions. But by the nature of the thermodynamic processes in the engine, it is not possible to obtain the same level of efficiency within the entire range of operation. Therefore, depending on the particular application, for example for power generation, the rotational speed would be constant and dictated by the electrical generating machine. Gas turbine engine consists of various components which are linked together in such a way that there exists a mechanical and thermodynamic interdependence among some components. This means that some operational compatibility (matching) between components will be required for a steady state or equilibrium operation. The steady state of gas turbine engine for power generation can be achieved by the matching of its compressor and turbine. The usual approach of matching the compressor and the turbine is usually based on using an iterative procedure to determine the turbine operating points which are then plotted on the compressor characteristics. The draw back of this process is being laborious and time consuming. The new approach developed overcomes this by superimposing the turbine performance characteristics on the compressor performance characteristics while meeting the components matching conditions. This can be done by introducing a new mass flow dimensionless parameter. Superimposing the turbine map on the compressor map cannot be totally accepted until both maps axes (the abscissa and the ordinate) are identical. This paper explains the new approach adopted to a single shaft gas turbine engine. Theoretically, the developed techniques can be applied to other gas turbine engines.
\end{abstract}

Keywords: Gas Turbine Off-Design, Gas Turbine Performance, Component Matching

\section{Introduction}

Gas turbines are often required to operate at different power levels and under varying environmental conditions. But, it is not possible to obtain the same level of power output and efficiency within the entire range of operation. The gas turbine may be designed for optimised operation at given power level and specified conditions. The power level and expected thermal efficiency are chosen to correspond to those conditions under which the engine operates for most of its life. The values of the characteristic parameters at that point are termed as the design point.

Usually, a set of independent variables, which exclusively determine the performance of the engine, will be associated with this region (envelope). For a fixed geometry engine, these may be chosen as pressure ratio, turbine inlet temperature, rotational speed and air mass flow rate. This set is complete but not unique.

The gas turbine engine consists of various components, which are linked together in such a way that there exists a mechanical and thermodynamic interdependence among some components. This means that some operational compatibility (matching) between components will be required for a steady state or equilibrium operation. This requirement reduces the range of the operating conditions for the components. But it is possible to define a subset of the engine's operating envelope such that every point in this subregion is an equilibrium working point. These working points can be mapped on the respective components characteristics. The design point values are elements of this region, which yield the best thermal efficiency. Any point in the region 
other than the design point represents an off-design condition.

The off-design problem may therefore be stated as the determination of a point in this region that corresponds to some specified conditions at which the equilibrium criteria would be satisfied but at reduced value of thermal efficiency. Since the operating points of the individual components can be determined by using the given values of some characteristic parameters, the off-design problem reduces to computing the values of these parameters, which would satisfy the equilibrium criteria. This procedure is demonstrated in the analysis given hereafter.

\section{Matching Procedure}

Several researchers presented different methods for matching gas turbines components in the open literature. Among them the work by Flack [1] in which he presented a method of matching gas turbine components for an aeroderivative power generation gas turbine as an exercise for students in the classroom. Matching is accomplished by simultaneously solving the matching closure equations along with the component maps (either mathematical models or graphical data). Also, he claimed that this method is a tool in which a student can select components to optimize the overall performance and can predict off-design performance of a power generation unit. Kong et al. [2] work were on fuzzy logic and they used the fuzzy approaches for searching optimal component matching point in gas turbine performance simulation. Gugau and Roclawskip [3] have used an optimization software for producing the matching maps that fits turbine and compressor (turbocharger) to the internal combustion gasoline engine, and keeps fuel consumption low at all engine speeds. Tsoutsanis et al. [4] developed a novel compressor map generation method, with the primary objective of improving the accuracy and fidelity of the engine model performance prediction. A new compressor map fitting and modelling method is introduced to simultaneously determine the best elliptical curves to a set of compressor map data. The coefficients that determine the shape of compressor maps' curves have been analyzed and tuned through a multi-objective optimization algorithm in order to meet the targeted set of measurements. The proposed component map generation method is developed in the object oriented Matlab/Simulink environment and is integrated in a dynamic gas turbine engine model. The accuracy of this method is evaluated for off-design steady state and transient engine conditions. The proposed compressor map generation method has the capability to refine current gas turbine performance prediction approaches and to improve modelbased diagnostic techniques.

Considering a simple radial gas turbine used for electrical power generation application schematically showed in figure 1 . The performance of the compressor and the turbine are completely known by their characteristics maps as shown in figure 2 and figure 3 . The data used in producing theses plots were taken from actual tests experiments on type $01 \mathrm{C}$. A.V compressor and inward radial turbine fitted with a nozzles casing provided by Bhinder [5].

In this radial gas turbine engine, the component's matching should meet the following conditions:

i. The compressor shaft speed = the turbine shaft speed, $N_{c}=N_{t}=N$

ii. The gas mass flow through turbine is the sum of the air mass flow through compressor and the fuel mass flow, $\dot{m}_{g}=\dot{m}_{a}+\dot{m}_{f}$

iii. Assuming that the pressure loss in the combustion chamber is a constant small percentage $\zeta_{c c}$ of the combustion chamber inlet pressure, $P_{03}=\left(1-\zeta_{c c}\right) P_{02}$

iv. Inlet and exhaust pressure losses are too small and can be ignored, $P_{04}=P_{01}$

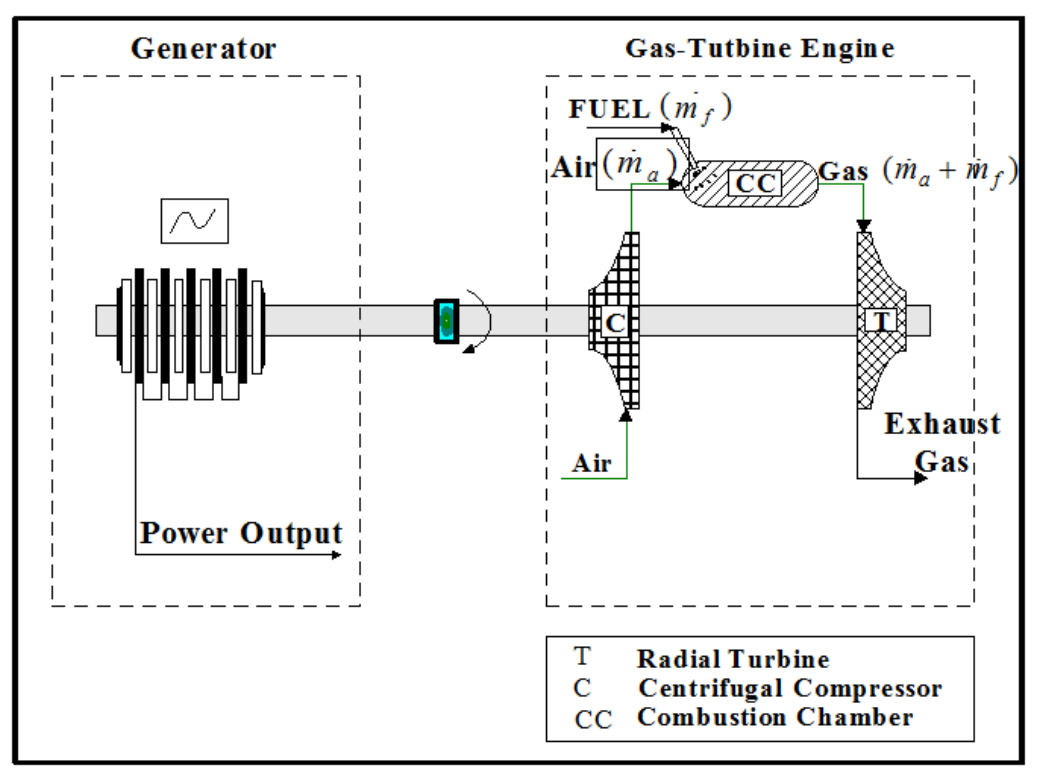

Figure 1. Schematic diagram of simple radial gas turbine engine. 
It should be noted that the second condition is subject to modification in that it is common practice to bleed air from the compressor at various stations to provide cooling air for bearings and turbine blade cooling. Quiet often it is sufficiently accurate to assume that the bleed air equals the fuel flow, and therefore the mass flow is the same throughout the compressor and the turbine. i. e. $\dot{m}_{g}=\dot{m}_{a}=\dot{m}$

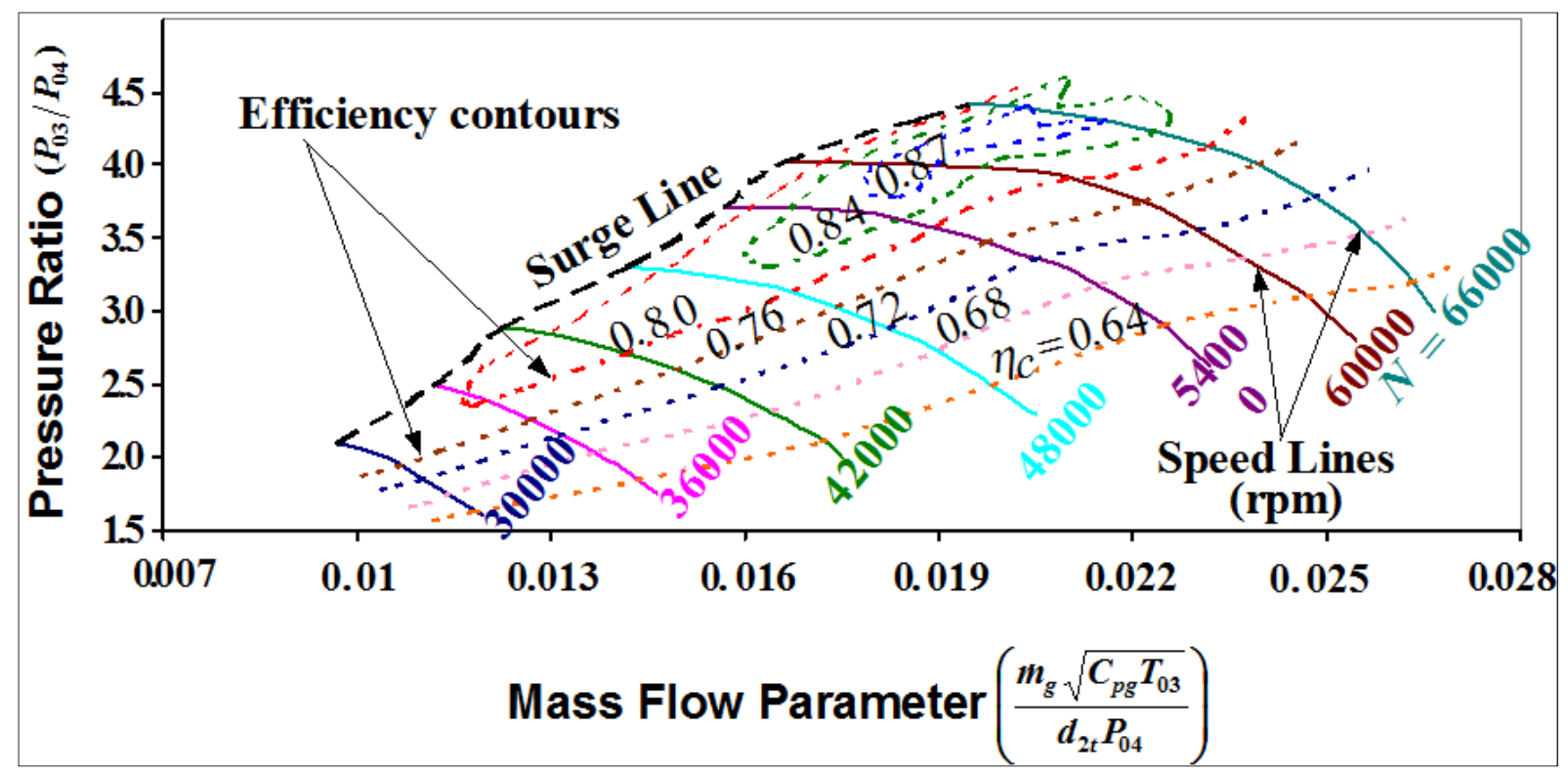

Figure 2. General Compressor Characteristics map.

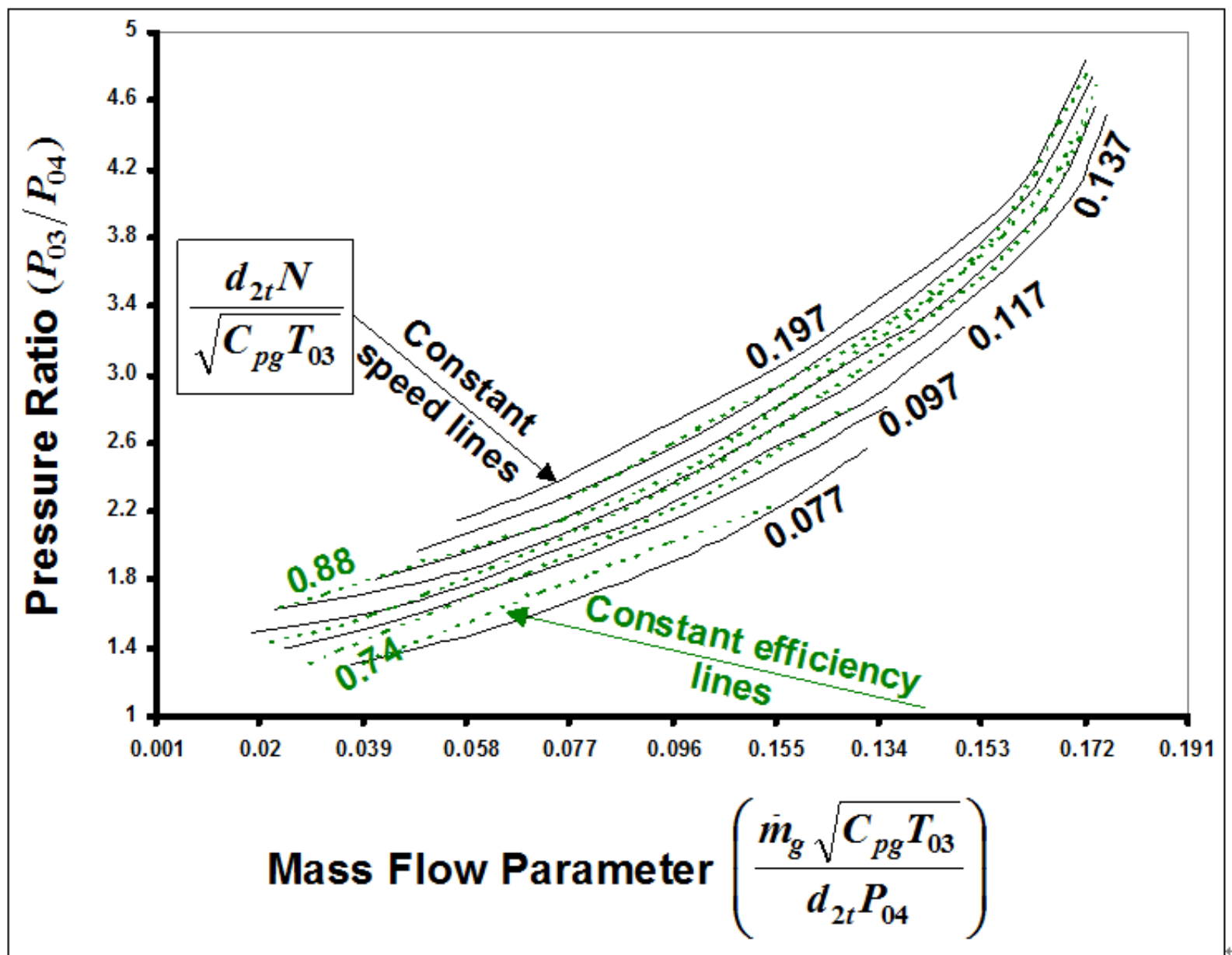

Figure 3. Turbine Characteristics map. 
The steady state or equilibrium operation of this gas turbine engine can be achieved by the matching of its compressor and turbine. Matching the compressor and the turbine can be done by superimposing the turbine performance map on the compressor map while meeting the components matching conditions. This matching procedure is schematically shown in figure 4.

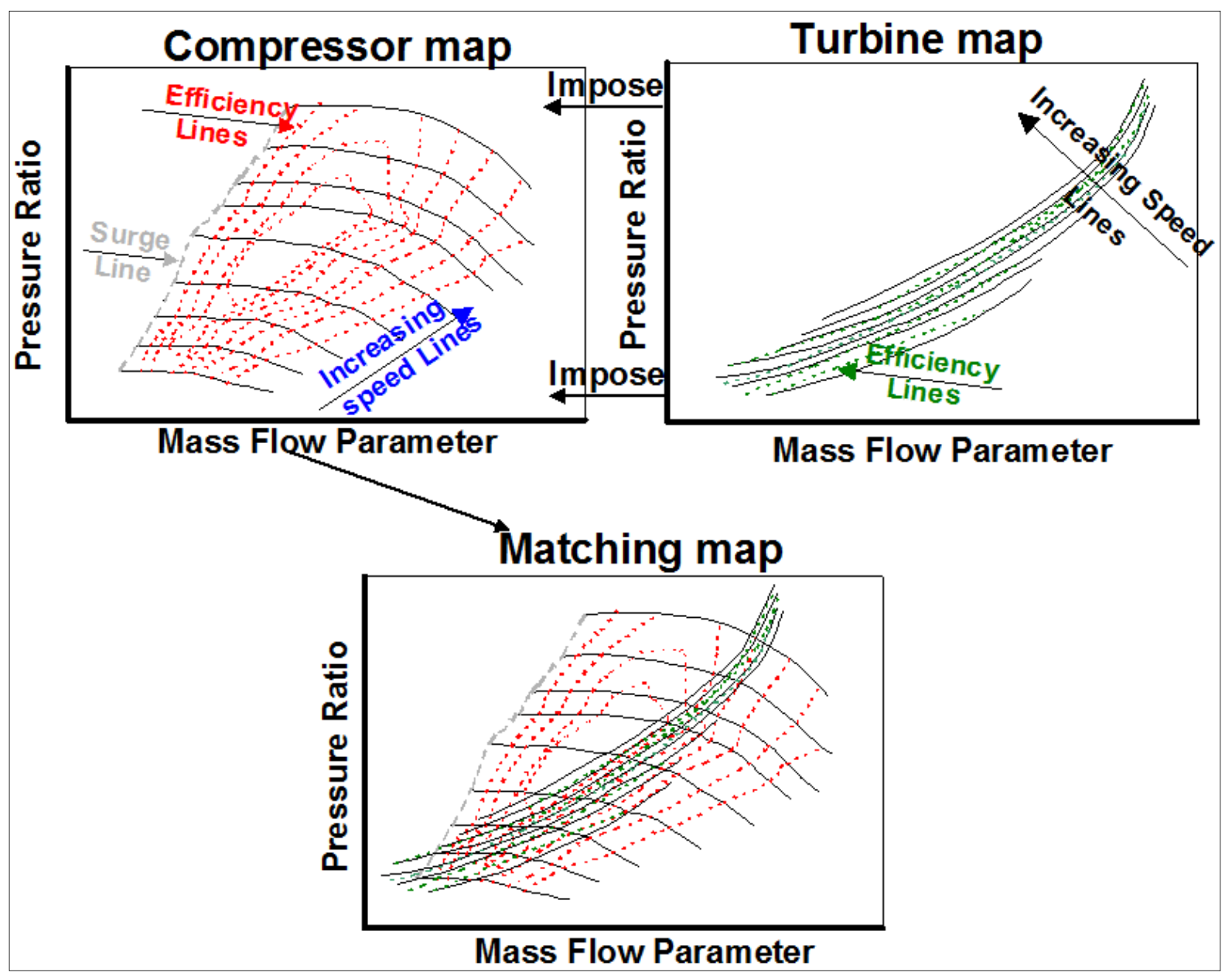

Figure 4. Compressor-turbine matching procedure.

Superimposing the turbine performance map on the compressor map can be achieved by applying the usual procedure of using iterative process Refs. $[6,7,8]$ which is a long process or by applying the new approach of making both map's axes (the abscissa and the ordinate) being identical.

The main difficulty here is that of temperatures: $T_{01}$ for the compressor and $T_{03}$ for the turbine are different. The procedure to overcome this problem was solved by introducing a new dimensionless parameter named as the matching parameter $\left[\frac{\dot{m} N}{d_{2 c} P_{01}}\right]$. The derivation of this parameter is described in the following section.

\subsection{The Centrifugal Compressor}

Based on figure 2 shown previously which illustrates the general compressor characteristics map. The mass flow dimensionless parameter $\frac{\dot{m}_{a} \sqrt{C_{p a} T_{01}}}{d_{2 c}^{2} P_{01}}$ represents the abscissa part of figure 2. The proposed matching dimensionless parameter $\left[\frac{\dot{m}_{a} N}{d_{2 c} P_{01}}\right]$ is derived by multiplying the mass flow dimensionless parameter with the dimensionless speed parameter $\frac{d_{2 c} N}{\sqrt{C_{p a} T_{01}}}$ as shown in Eqn. 1:

$$
\left[\frac{\dot{m}_{a} \sqrt{C_{p a} T_{o 1}}}{d_{2 c}^{2} P_{o 1}}\right] \times\left[\frac{d_{2 c} N}{\sqrt{C_{p a} T_{o 1}}}\right]=\left[\frac{\dot{m}_{a} N}{d_{2 c} P_{o 1}}\right]
$$

The ordinate i.e. the pressure ratio parameter $P_{o 2} / P_{o 1}$, remains unchanged. Once these transformations had been made, the compressor characteristics map was plotted again in terms of these new parameters as shown in figure 5. It should be noted that the characteristics map does not change much. 


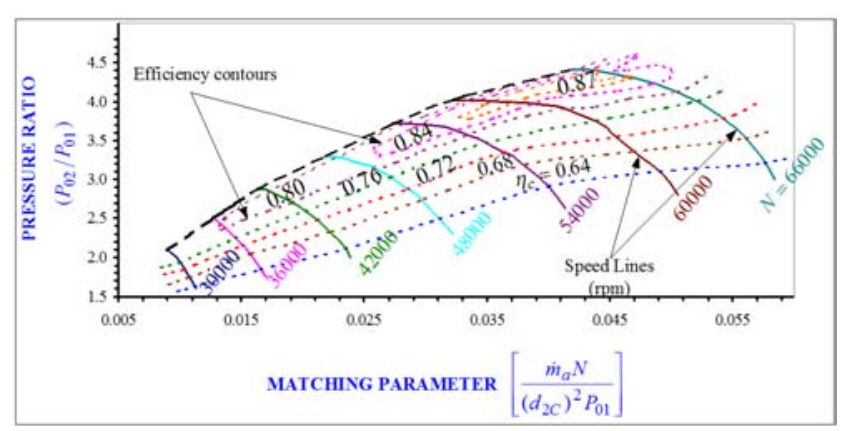

Figure 5. Centrifugal compressor map after transformation.

\subsection{The Radial Turbine}

Based on figure 3 shown previously, which illustrates the general turbine characteristics map. The mass flow dimensionless parameter $\frac{\dot{m}_{g} \sqrt{C_{p g} T_{03}}}{d_{2}^{2} P_{03}}$ represents the abscissa part of figure 3 . The proposed matching dimensionless parameter $\left[\frac{\dot{m}_{g} N}{d_{2 c} P_{04}}\right]$ is derived by multiplying the mass flow parameter with the dimensionless speed parameter, turbine pressure ratio and the ratio of the turbine rotor diameter to compressor impeller diameter as shown in Eqn. 2:

$\left[\frac{\dot{m}_{g} \sqrt{C_{p g} T_{03}}}{d_{2 t}^{2} P_{03}}\right] \times\left[\frac{d_{2 t} N}{\sqrt{C_{p g} T_{03}}}\right] \times\left[\frac{P_{03}}{P_{04}}\right] \times\left[\frac{d_{2 t}}{d_{2 c}}\right]=\left[\frac{\dot{m}_{g} N}{d_{2 c} P_{04}}\right]$
To satisfy the compressor-turbine matching conditions specified previously, i.e. $\dot{m}_{g}=\dot{m}_{a}=\dot{m}$ and $P_{04}=P_{01}$. Then the developed matching parameter of the turbine is equal to the developed matching parameter of the compressor.

$$
\text { i.e. } \frac{\dot{m}_{g} N}{d_{2 c} P_{04}}=\frac{\dot{m}_{a} N}{d_{2 c} P_{01}}
$$

For the turbine pressure ratio parameter, the ordinate axis of the turbine characteristics map $\left[P_{03} / P_{04}\right]$ for matching is transformed into the pressure ratio across the compressor as shown in Eqn. 4:

$$
\left[\frac{P_{03}}{P_{04}}\right] \times\left[\frac{1}{1-\xi_{c c}}\right] \times\left[\frac{P_{04}}{P_{01}}\right]=\left[\frac{P_{02}}{P_{01}}\right]
$$

Note that:

$$
P_{03}=\left(1-\xi_{c c}\right) P_{02}
$$

And

$$
P_{04}=P_{01}
$$

Once these transformations had been made, the turbine characteristics map was plotted again in terms of these new parameters as shown in figure 6 .

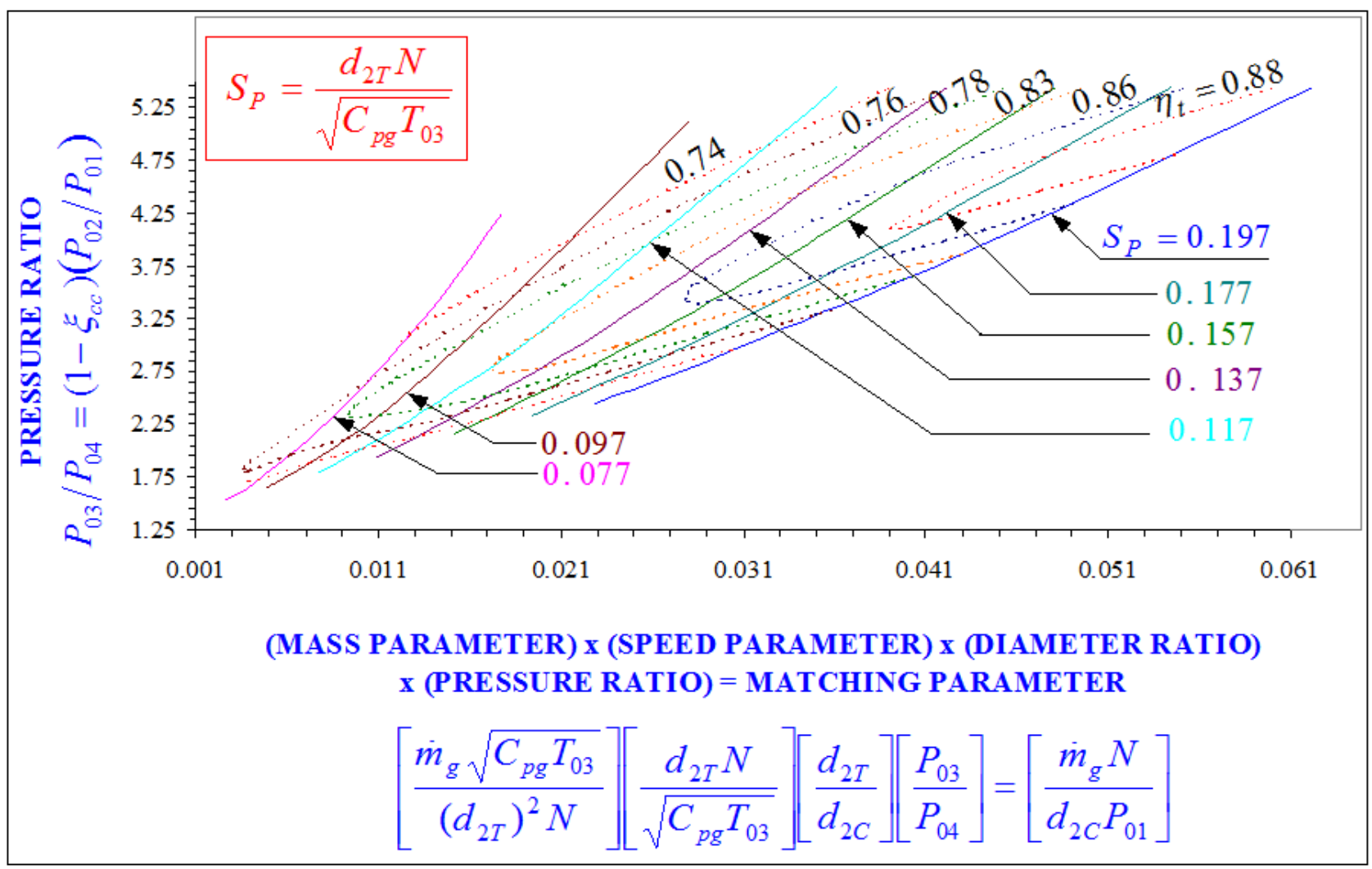

Figure 6. Radial turbine map after transformation. 


\subsection{Compressor-Turbine Matching}

It can be seen from the graphical plots of compressor and turbine performance maps that the abscissa and the ordinate of these maps are identical. Therefore, it is clear that the turbine map could be superimposed on the compressor map to produce a complete compressor-turbine matching map as shown in figure 7.

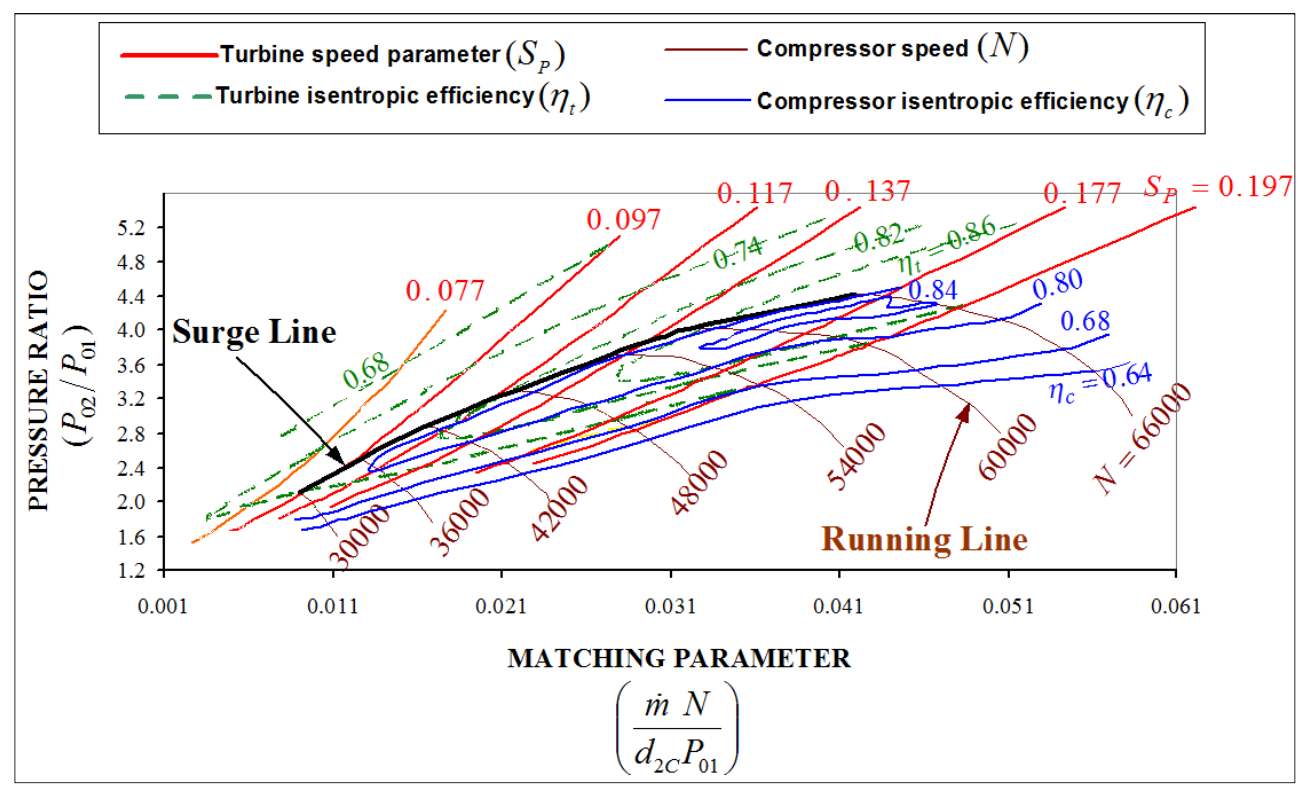

Figure 7. Complete compressor-turbine matching map.

\section{Results and Discussion}

The resulting matching map shown in figure 7 is a very useful tool in predicting the overall performance of matched components, i.e. the gas turbine design and off-design performance. Using the compressor-turbine dimensionless speed intersection points, where the speed is the same ( $N_{c}=N_{t}$ ), the turbine inlet temperatures $T_{03}$ of the gas turbine speed can be easily calculated based on the speed parameter $S_{P}=\frac{d_{2 T} N}{\sqrt{C_{p a} T_{03}}}$ from figure 7. for any speed. The turbine inlet temperature $T_{03}$ lines of $750 \mathrm{~K}$ and $1000 \mathrm{~K}$ were computed and drawn in Figure 8. It can be seen that the changes of constant $T_{03}$ lines at various pressure ratios are linear and showed divergence at higher values of speed and pressure ratios. The area between these two lines represents the accepted working range for the gas turbine engine.

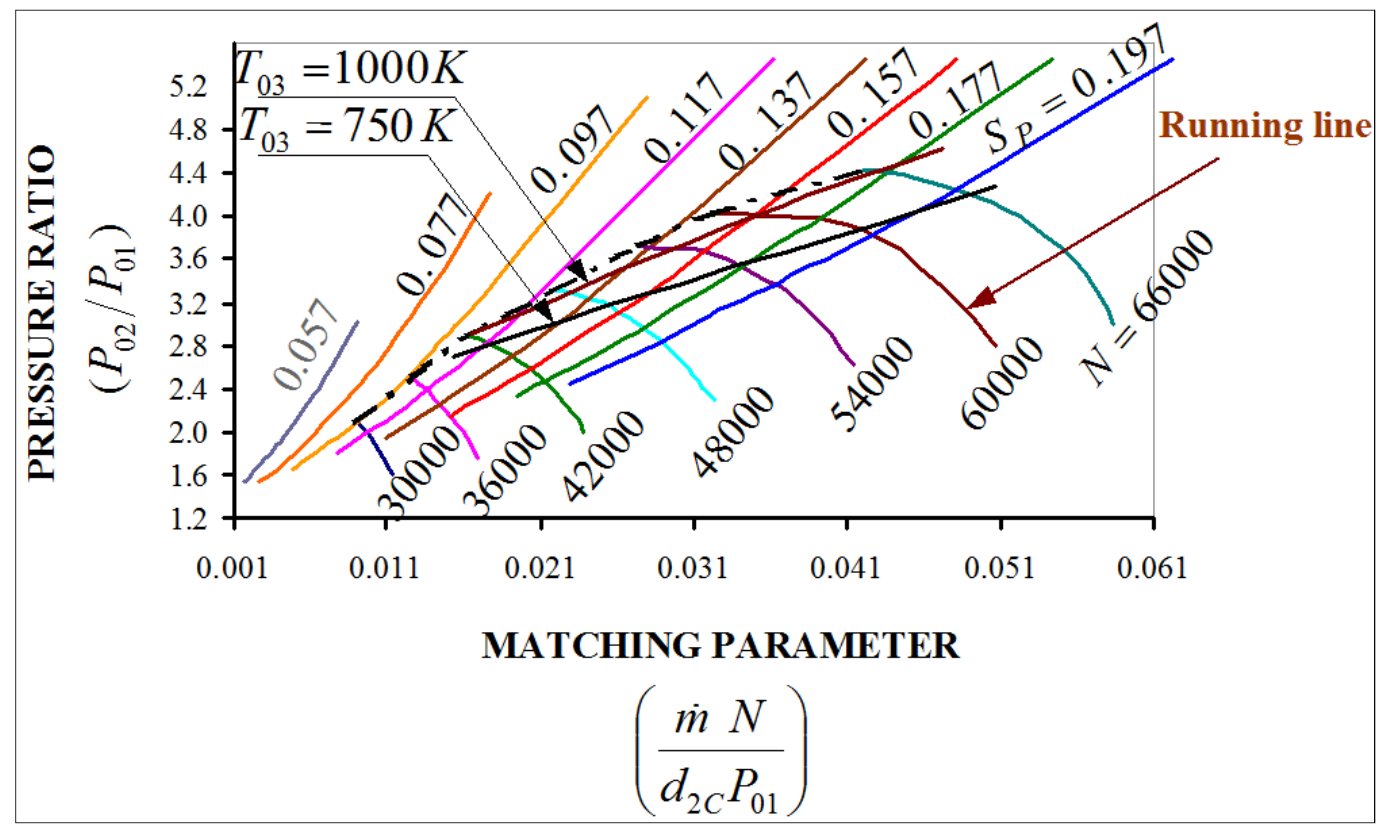

Figure 8. Constant turbine inlet temperatures $T_{03}$. 
At any point within the matching range, the following parameters listed in Table 1 are computed according to Eqns. (7-13) given by $[9,10]$.

Table 1. Performance parameters of gas turbine engine.

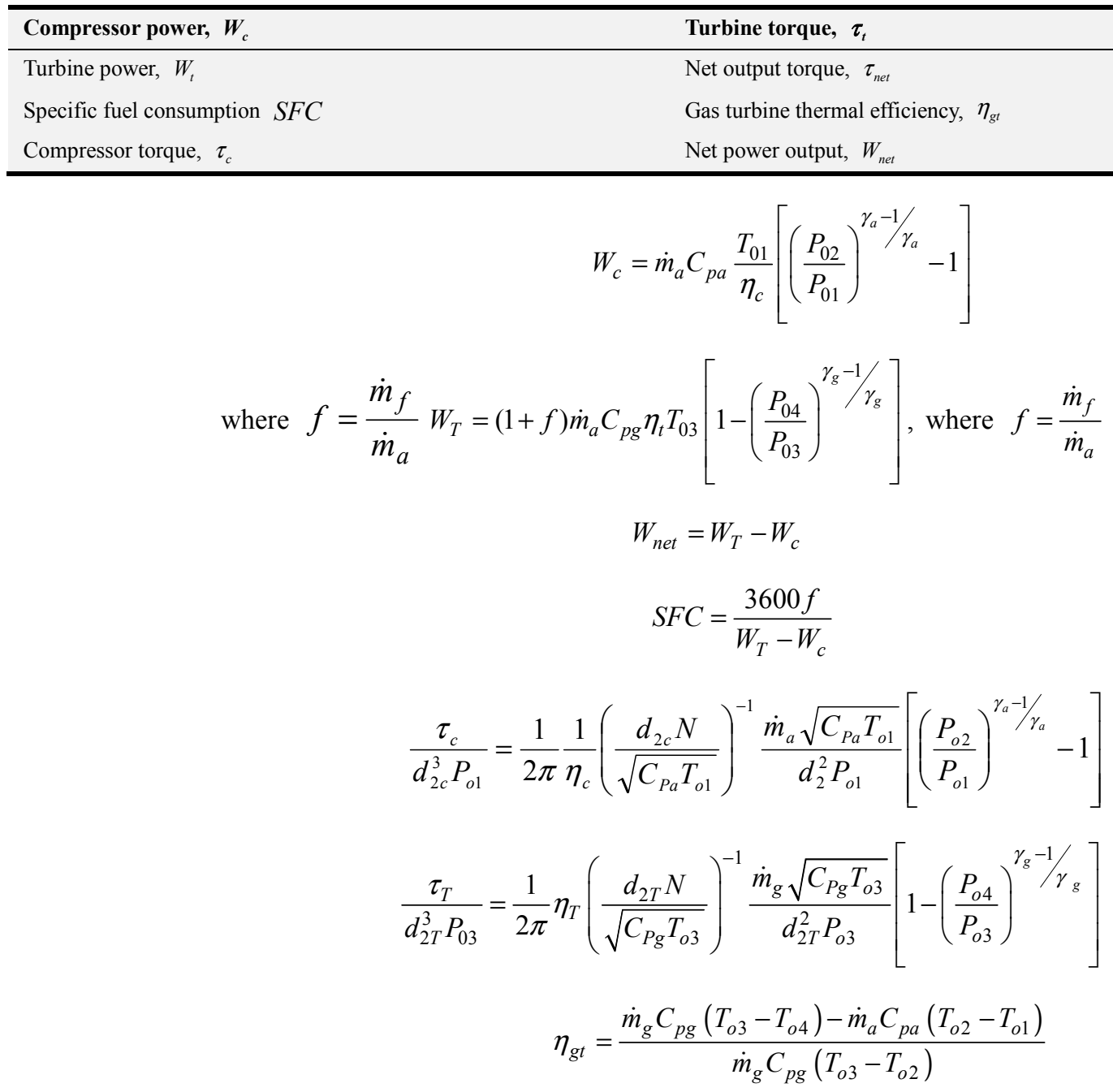

For a power generation driven by radial gas turbine engine, let's consider any running line, for example, the line of speed $60000 \mathrm{rpm}$ was extracted from figure 7 , for clarity, it is depicted in figure 9.

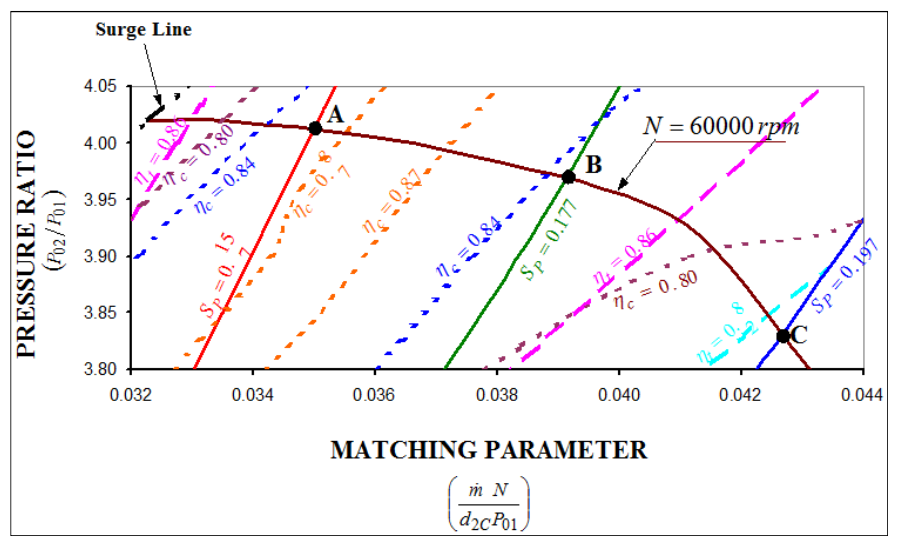

Figure 9. Matching characteristics of the design speed line at $60000 \mathrm{rpm}$.

It can be seen that all the matching values of the engine components at the design speed are known and are used to predict the engine performance such as thermal efficiency, specific fuel consumption and engine torque at design and off-design 
conditions. Based on the graphical analysis, the above parameters can be calculated within the specified working range. The output results are plotted as shown in figure 10 and figure 11 which provides important information about the performance of the gas turbine at design and off design points.

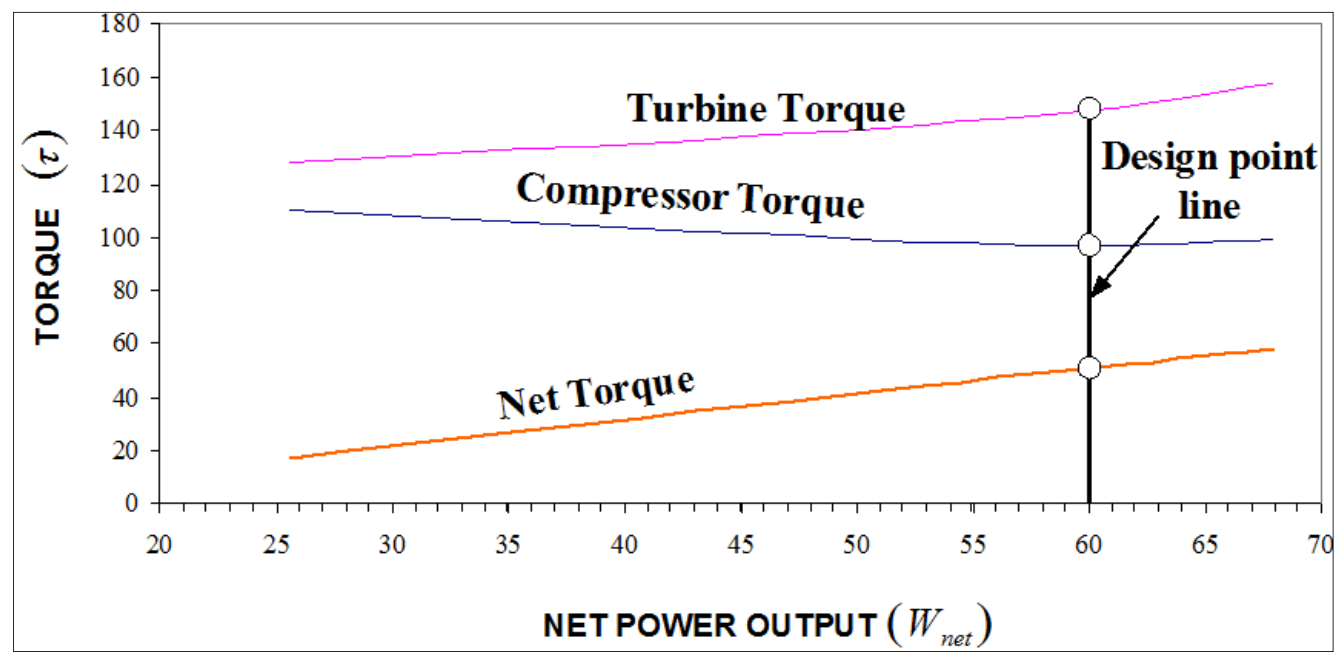

Figure 10. Variation of engine torque at design and off design conditions $60000 \mathrm{rpm}$

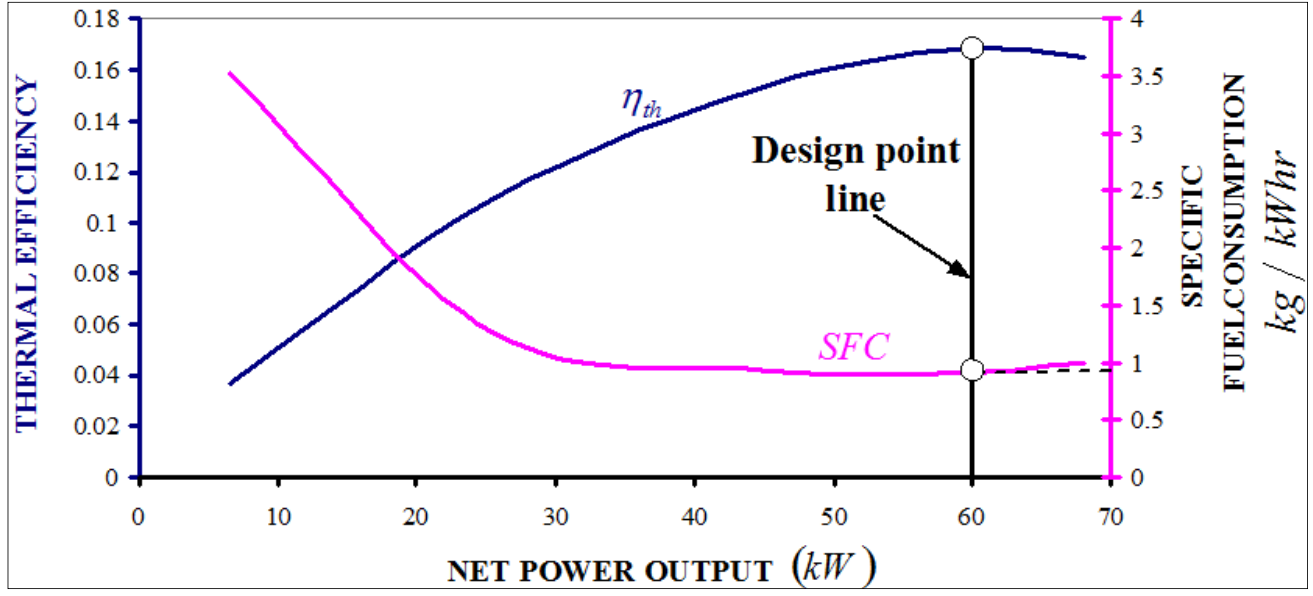

Figure 11. Variation of engine thermal efficiency and SFC at design and off-design conditions at $60000 \mathrm{rpm}$

\section{Concluding Remarks}

Applying this new approach leads to the determination of the operating range (envelope) and running line of the matched components. Also, the proximity of the operating points to the compressor surge line (how close the operating points to the surge line) is presented. However, it was concluded that the maximum operating point occurs at the maximum turbine inlet temperature $\left(T_{o 3}\right)$.

The most important it can be concluded from this work whether the gas turbine engine is operating in a region of adequate compressor and turbine efficiencies. Finally, this method saves time and work effort compared to the usual iterative process.

\section{Nomenclature}

$C_{P} \quad$ Specific heat at constant pressure $\gamma \quad$ Ratio of specific heat

$\dot{m} \quad$ Mass flow rate

$w, W \quad$ Specific work output, work output

$P \quad$ Pressure

$T \quad$ Temperature

$\eta \quad$ Efficiency

$\tau \quad$ Torque

$L C V \quad$ Lower calorific value

$F \quad$ Fuel to air ratio

d Diameter

$N \quad$ Rotational speed

$\xi \quad$ Loss of stagnation pressure

$S_{P} \quad$ Turbine dimensionless speed parameter

Subscripts

1. Compressor inlet

2. Compressor exit

3. Turbine inlet

4. Turbine exit 


$\begin{array}{ll}o & \text { Stagnation } \\ g & \text { Gas } \\ g t & \text { Gas turbine } \\ a & \text { Air } \\ c & \text { Compressor } \\ c c & \text { Combustion chamber } \\ t & \text { Turbine } \\ f & \text { Fuel air ratio }\end{array}$

\section{References}

[1] Flack R., "component matching analysis for a power generation gas turbine: classroom applications", ASME Turbo Expo 2002: Power for Land, Sea, and Air, Vol. 1: Turbo Expo 2002, Amsterdam, The Netherlands, June 3-6, (2002), 859-866.

[2] Kong C., Ki J., Kang M., "Fuzzy approaches for searching optimal component matching point in gas turbine performance simulation", J. Eng. Gas Turbines Power, Vol. 126, issue 4, (2004), 741-747.

[3] Gugau M., and Roclawski, H., "On the Design and Matching of Turbocharger Single Scroll Turbines for Pass Car Gasoline Engines, J. Eng. Gas Turbines Power, Vol. 136, Issue 12, (2014).
[4] Tsoutsanis E., Meskin N., Benammar M., Khorasani K., “An Efficient Component Map Generation Method for Prediction of Gas Turbine Performance" ASME Turbo Expo 2014: Turbine Technical Conference and Exposition Volume 6: Ceramics; Controls, Diagnostics and Instrumentation; Education; Manufacturing Materials and Metallurgy, Düsseldorf, Germany, June 16-20, 2014.

[5] Richard T. C. Harman "Gas turbine Engineering". First Edition, 1981.

[6] Walsh, P and Fletcher, P. "Gas Turbine Performance" 1998.

[7] Cohen, H. Rogers, G F C and Saravanamutto, H. I. H. "Gas Turbine Theory". Second Edition, 1972.

[8] Bhinder F. S., "Design parameters of centripetal turbine in nonsteady flow" PhD thesis, King's college, London, March, 1974.

[9] Ebaid, M. S. Y. "Design and construction of small gas turbine to drive a permanent magnet high speed Generator". PhD Thesis, University of Hertfordshire, 2002.

[10] Al-Hamdan, Q. Z. M. "Design criteria and performance of gas turbines in a combined power and power (CPP) plant for electrical power generation" $\mathrm{PhD}$ Thesis, University of Hertfordshire, 2002. 